\title{
Hesio Cordeiro: \\ um gigante da Saúde Coletiva
}

| ${ }^{1}$ José Gomes Temporão |

${ }^{1}$ Centro de Estudos Estratégicos, Fundação Oswaldo Cruz. Rio de Janeiro-RJ, Brasil (gomestemp51@gmail.com). ORCID: 0000-0001-7162-2905
Recebido em: 02/10/2019
Aprovado em: 03/03/2020
Revisado em: 23/08/2021

DOI: http://dx.doi.org/10.1590/S0103-73312021310304

A última vez que estive com Hesio foi em sua casa, há cerca de dois anos. Foi uma visita difícil, pois se o homem estava ali com seu sorriso e magnetismo, sua mente parecia já estar divagando em outra dimensão.

Com sua trajetória rica e diversificada, decidi por me referir aqui a apenas três momentos em que a participação dele foi, na minha opiniáo, decisiva para os rumos da política de saúde em nosso país. Momentos em que tive o privilégio de estar ao seu lado.

O primeiro engloba a militância na saúde pública, no Cebes (Centro Brasileiro de Estudos de Saúde), e como seu aluno na Ensp/Fiocruz.

Náo lembro exatamente da primeira vez que me encontrei com Hesio. Mas havia sido seu aluno em 1978 durante o Curso de Especialização em Saúde Pública, na Escola Nacional de Saúde Pública da Fiocruz (ENSP-Fiocruz). Já tinha lido alguns de seus textos, escutando-o em eventos e reuniooes, mas não tínhamos ainda uma relação pessoal. À época eu era um jovem estudante do curso de Medicina da UFRJ e tinha uma certa timidez ao conviver com as "feras" do movimento sanitário como Hesio, Arouca, Reinaldo Guimarães, Jaime Oliveira, Sonia Fleury e tantos outros. Nosso 
primeiro encontro fora da sala de aula possivelmente aconteceu em alguma reuniáo do movimento de renovação médica (REME) ou do Cebes, ali entre 1977 e 1978.

Recordo que ele se destacava pela simpatia, inteligência, articulação, e fazia análises que iam muito além da retórica militante da época. Outro aspecto que sempre me chamou a atenção era a percepção de estarmos diante de um médico com boa formação clínica falando de saúde coletiva, o que para mim fazia muita diferença.

Desse período um momento se destaca. No dia 31 de julho de 1978, o professor José Luís Fiori compareceu à reunião da diretoria do CEBES-RJ, com a proposta de criação de uma "frente pela democratizaçaao" do país, como consta da ata daquela reunião:

[...] diante da atual abertura política e da recente mobilização da categoria médica em cima de pautas específicas, onde percebe-se a ausência de um tipo de proposta mais abrangente que seja lançada para o debate e que se situe entre as propostas mais acadêmicas e mais políticas, surge a ideia de se colocar para o debate, a proposta de uma plataforma mínima que lograsse consenso entre os médicos, e que pudesse ser viabilizada por um possível governo de transição. Esta proposta seria elaborada pelas várias entidades médicas e seria lançada em ato público em vários estados do país. (CEBES, 1978).

A partir daí, tomou corpo no Cebes o Movimento pela Democratização da Saúde e a base para os debates e iniciativas que se seguiram passou a ser o documento redigido por José Luís Fiori, Reinaldo Guimarães e Hesio Cordeiro, cujo título era "A questão democrática na área da Saúde", e que viria a se transformar em referência seminal da Reforma Sanitária Brasileira, pautando a estratégia programática do movimento sanitário até a Constituinte.

Em 1979, o CEBES contou com Sergio Arouca para apresentá-lo como seu documento oficial no $1^{\circ}$ Simpósio de Política de Saúde da Câmara dos Deputados. O simpósio, que reuniu conferências de várias figuras ilustres, entre elas os professores Roberto Santos, Carlyle Guerra de Macedo e Paul Singer, teve como debatedores Carlos Gentile de Mello, Hesio Cordeiro, Nelson Rodrigues dos Santos e Cecília Donnangelo, entre outros.

Destaco trecho da intervenção de Hesio comentando a conferência de Roberto Santos, por achar o conteúdo bastante atual:

Este Simpósio, a partir da intervenção do Prof. Roberto Santos nos coloca em face de um desafio: no campo das políticas sociais, o que significa, hoje, a democratizaçãa?

Se entendo que, nestes últimos 15 anos, as políticas sociais não tiveram caráter igualitário e redistributivo, e sim um caráter reconcentrador e desigual, coloco como grande questão 


\begin{abstract}
o significado do debate que hoje se instaura sobre democracia, qual o papel da saúde, qual o significado da saúde nesse âmbito; o que significará, para os partidos que aí estáo, ou para os partidos que se reestruturarão, desenvolver uma política social e uma política de saúde coerente com seus objetivos. E mais, a mim me preocupa o que poderia significar, dado que esta política não atende aos interesses populares, nem atende ao caráter igualitário esperado das políticas sociais, os rumos de uma política de oposição e de uma política alternativa para enfrentar os problemas apontados. Significaria, em outros termos, não exercer a política como a arte do possível, ou a política como a arte da conciliaçáo, a política com arte, no caso da saúde, dessa convivência ambígua entre o setor público e o privado; significaria... a política como travessia, travessia no sentido de se lograr, pelo desenvolvimento, uma sociedade igualitária e, portanto, democrática, no seu âmbito econômico e social. (BRASIL, 1980, p. 39).
\end{abstract}

$\mathrm{Na}$ verdade, o documento do Cebes não constava da programação oficial do evento e foi apresentado como um tema livre sob o título de "Democratização e saúde: CEBES-Nacional”, mas seu impacto foi tão grande que, por consenso dos presentes, o texto passou a fazer parte do relatório final do encontro e acabou por dar o tom político ao evento.

O segundo momento é o do Hesio como pensador e pesquisador e de sua importante contribuição acadêmica para a compreensão da dinâmica capitalista no campo da saúde, através de seus estudos sobre as relaçôes entre a indústria farmacêutica e a prestação e consumo de açóes de saúde. Aí cunhou o termo complexo médicoindustrial e apontou o empresariamento crescente do espaço da prestação de serviços e açóes de saúde em nosso país, tornando-se objeto de sua tese de doutoramento.

O livro $A$ indústria da saúde no Brasil influenciou profundamente minha dissertação de mestrado, da qual ele foi orientador. Nessa obra, ele explora a questão dos padróes de consumo de medicamentos, o autoconsumo, e avança na conceituação do complexo médico-industrial.

Estávamos no início dos anos 80 e eu entrei para o mestrado em Saúde Pública da ENSP. E apresentei a ele um projeto de análise da publicidade de medicamentos pelos meios de comunicação de massa e seu impacto na construção de uma consciência negativa em saúde por parte dos trabalhadores de uma empresa metalúrgica da Baixada Fluminense, onde eu atuava como clínico. Embora o tema fosse para além do escopo do campo do planejamento e das políticas de saúde (o mestrado era em Políticas e Planejamento de Saúde), ele acolheu minhas inquietaçóes e esse estudo depois foi publicado pela editora Paz e Terra/Graal como um trabalho pioneiro sobre as relações entre saúde, meios de comunicação de massa e indústria farmacêutica. 
O terceiro momento vem com a Nova República e o fim da ditadura militar. Assume o Ministério da Previdência Social Waldir Pires, que nomeia Hesio Cordeiro como presidente do INAMPS. Tanto no Inamps quanto no MS, são constituídas equipes compostas por jovens sanitaristas defensores da proposta da saúde universal e democrática. Nesse contexto, o polo mais dinâmico do processo de unificação e descentralização do sistema de saúde se organiza no INAMPS, detentor do maior orçamento no campo da saúde e com grande peso político e assistencial. Na época, o MS não tinha a expressão econômica, tecnológica e política na saúde do país, como veio a acontecer posteriormente. Tudo girava em torno do INAMPS. É nesse momento que os sanitaristas penetram o chamado núcleo duro da saúde brasileira: o INAMPS. Hesio foi o primeiro sanitarista a ocupar sua presidência, e com ele assumi a Secretaria de Planejamento daquela instituição. Hesio então tinha pouco mais de 40 anos e eu pouco mais de 30. Éramos muito jovens e, sob sua liderança, enfrentamos o gigantesco desafio de preparar a saúde brasileira para o que viria a ser o SUS poucos anos depois.

O INAMPS estabeleceu uma nova política, as Açôes Integradas de Saúde (AIS) como estratégia de reorientação setorial ${ }^{1}$. As AIS se estruturam a partir de convênios com estados e municípios, fazendo a transferência pioneira de recursos financeiros da previdência social para a saúde universal, criando estruturas de pactuação e construçáo de consenso e de integração de redes, que antecedem as atuais estruturas dos Conselhos de Saúde e Comissóes Bipartites, além de estabelecer mecanismos de planejamento integrado entre INAMPS e MS. Foi um período de grandes inovaçóes.

Com Hesio, as AIS receberam um impulso sumamente importante, passando de 112 para 2.800 municípios envolvidos. Além disso, cabe destacar outras iniciativas da gestão Hesio no INAMPS:

- os serviços próprios do INAMPS começaram a ser efetivamente recuperados, depois de anos de deliberado sucateamento;

- as políticas de formação de recursos humanos e de apoio ao desenvolvimento científico e tecnológico para as açóes de saúde ganharam forte impulso;

- o apoio à implantação do CESTHE (Centro de Estudos em Saúde do Trabalhador) na Fiocruz;

- a prioridade para os serviços públicos, os Hospitais Universitários e as Misericórdias e demais órgãos filantrópicos; 
- a decisão corajosa e de grande envergadura política, que foi a implantação do Sistema Unificado Descentralizado de Saúde (SUDS), dando início ao processo de unificação pela base, buscando superar as controvérsias conjunturais da unificação no plano federal.

Por fim, foi na vigência da gestão de Hesio que se realizou a $8^{a}$ Conferência Nacional de Saúde, em março de 1986, consagrando os princípios mais caros do movimento sanitário: a saúde como direito de todos e dever do Estado; a universalização e integralidade na assistência à população; o sistema único, a descentralização e a participação e controle da população como elementos fundamentais a serem alcançados.

"Um gigante da Saúde Coletiva”! Foi assim que me referi a Hesio ao homenageálo durante evento realizado no Congresso da Abrasco em 2014. A atuação de Hesio ao longo de sua produtiva vida como professor, pesquisador, formulador, gestor e político vai, com sua personalidade e inteligência cativantes, muito além do que trouxemos, a bem da experiência democrática brasileira!

\section{Referências}

CENTRO BRASILEIRO DE ESTUDOS DE SAÚDE. Livro de Atas da diretoria do Núcleo Rio de Janeiro. Rio de Janeiro, 1978.

BRASIL. Congresso Nacional. Câmara dos Deputados. $1^{\circ}$ Simpósio sobre Política Nacional de Saúde. Brasília, 1980.

\section{Nota}

${ }^{1} \mathrm{Na}$ verdade, as AIS surgem como Programa de Ações Integradas de Saúde (PAIS) no contexto de reforma da assistência médica previdenciária no início dos anos 80 do século passado no Inamps, sob a liderança de Eleutério Rodrigues Neto. Em 1984, e após muita polêmica, em famosa reunião realizada em Curitiba, as AIS são reafirmadas como a "estratégia de reorientaçáo setorial". 